\title{
Falcine chondroma: illustrative case
}

\author{
Melissa M. J. Chua, MD, ${ }^{1}$ Stanley F. Bazarek, MD, PhD, ${ }^{1}$ David M. Meredith, MD, PhD, ${ }^{2}$ Liangge Hsu, MD, ${ }^{3}$ and Stephen C. Saris, MD ${ }^{1}$ \\ Departments of ${ }^{1}$ Neurosurgery, ${ }^{2}$ Pathology, and ${ }^{3}$ Radiology, Brigham and Women's Hospital, Harvard Medical School, Boston, Massachusetts
}

\begin{abstract}
BACKGROUND Chondromas are benign cartilaginous tumors that are rarely seen in the brain.
OBSERVATIONS A58-year-old woman had undergone routine brain imaging after a motor vehicle accident and was incidentally found to have a right falcine lesion. Contrast magnetic resonance imaging showed a mostly nonenhancing mass with discontinuous rim enhancement. She was taken to the operating room and pathology revealed a chondroma.
\end{abstract}

LESSONS Falcine intracranial chondromas are rare and typically misdiagnosed as meningiomas. Chondromas should be in the differential for patients presenting with nonenhancing falcine lesions.

https://thejns.org/doi/abs/10.3171/CASE20124

KEYWORDS parasagittal; falcine; falx; chondroma

Chondromas are rare, slow-growing, benign cartilaginous tumors that are usually found in the extremities. However, they can occur intracranially, commonly arising from the skull base at the sphenoethmoidal, sphenopetrosal, sphenooccipital, or petrooccipital synchondroses. ${ }^{1,2}$ Intracranial chondromas account for $0.2 \%$ of all intracranial tumors and were first reported by Hirschfeld in $1851 .{ }^{3-9}$ Rarely, intracranial chondromas can arise from the falx, and we present a middle-aged woman with such a condition. $6,7,10$

\section{Illustrative Case}

A 58-year-old right-handed woman presented to an outside emergency department with right-sided headaches after a motor vehicle accident. She had no symptoms referable to the mass, and her neurological examination was normal.

\section{Radiographic Findings}

A head computed tomography (CT) scan demonstrated a 4-cm right falcine, calcified extraaxial lesion with leftward displacement of the superior sagittal sinus (Fig. 1). A contrast magnetic resonance imaging (MRI)/magnetic resonance venography scan showed a T1 isointense lesion with patency of the superior sagittal sinus (Fig. 2).

\section{Operative Course}

The tumor was highly calcified and minimally vascular and originated from the falx. The initial impression was meningioma.
Postoperatively, the patient woke up without any new neurological deficits and was discharged home.

\section{Pathology Findings}

Microscopic examination of the lesion demonstrated wellcircumscribed lobules of mature hyaline cartilage with regions of calcification surrounded by a thin layer of dura (Fig. 3). The chondrocytes showed no cytological atypia, and there was no increased
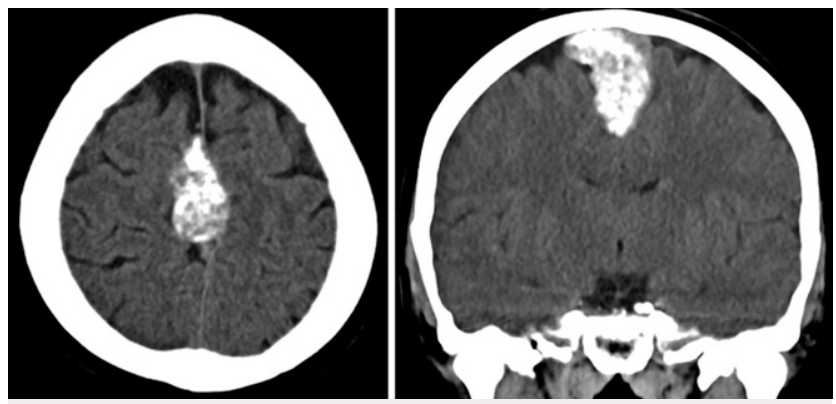

FIG. 1. Noncontrast CT in the axial (left) and coronal (right) planes demonstrating a highly calcified falcine mass. 

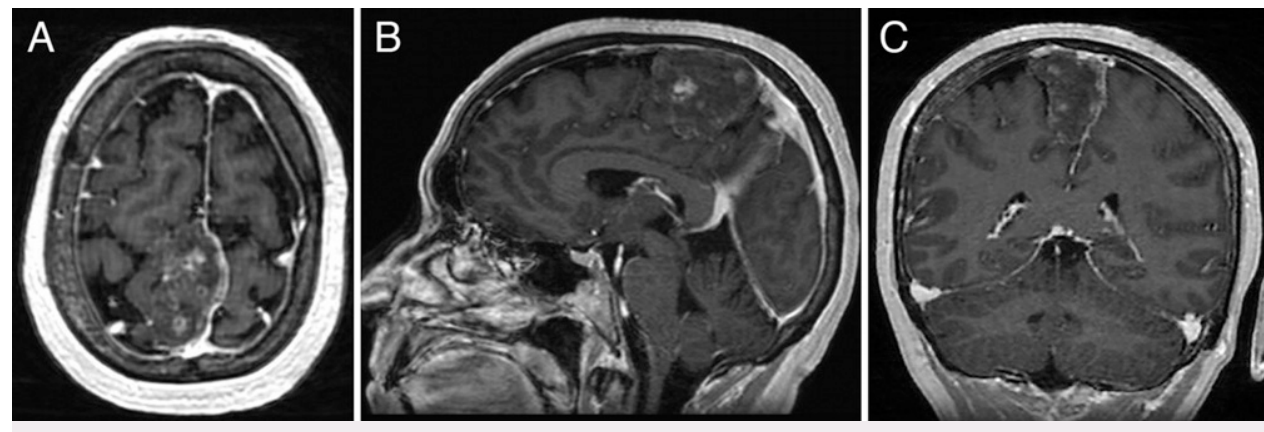

FIG. 2. Preoperative MRI T1-weighted postcontrast images in the axial (A), sagittal (B), and coronal (C) planes.

cellularity or overt proliferative activity to suggest a malignant process. No evidence of meningioma or other pathological processes were observed in the specimen, confirming the diagnosis of chondroma.

\section{Discussion}

The origin of intracranial chondromas is unknown. Theories include origination from embryonic rests of synchondrosis cartilage cells, metaplastic meningeal fibroblasts and perivascular mesenchymal tissue, and ectopic embryological rests or displacement of cartilaginous elements secondary to trauma or inflammation. ${ }^{4-7,11-16}$ It can also be associated with systemic cartilage tissue diseases including Ollier disease and Maffucci syndrome. ${ }^{17,18}$

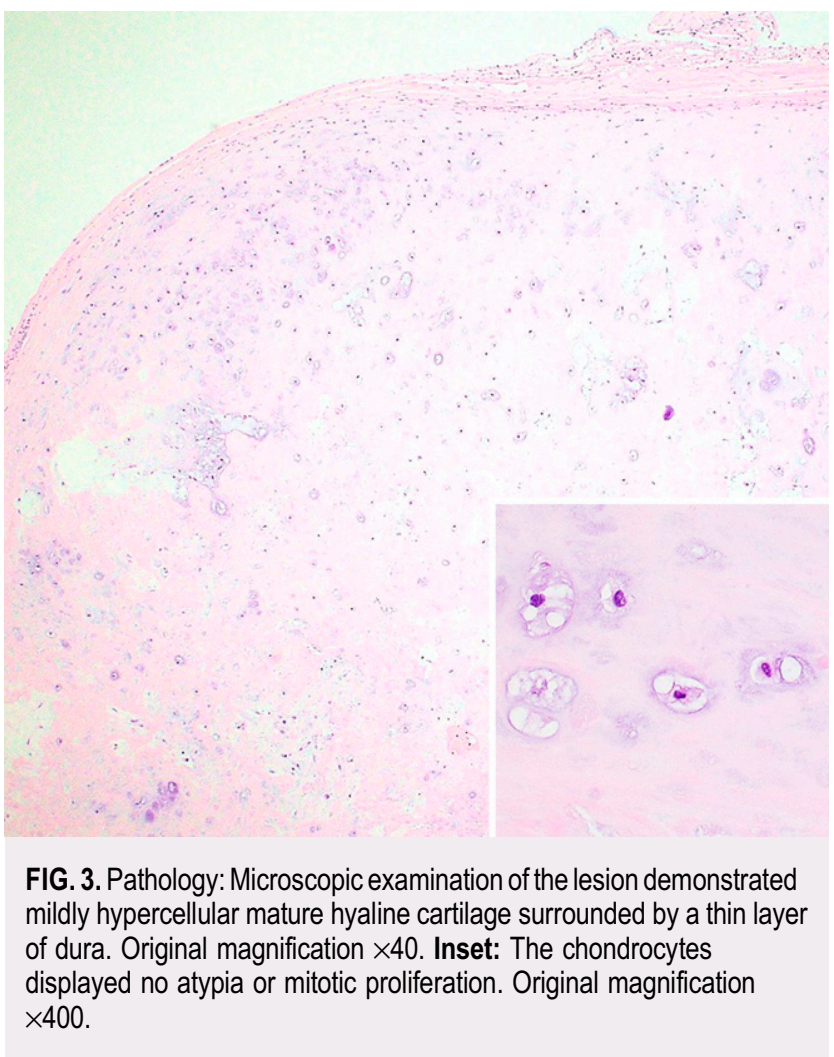

\section{Clinical Presentation}

Headaches are the most common presenting symptom of intracranial chondromas, followed by seizures or focal neurological deficits. $^{6}$

\section{Imaging Features}

When the imaging features of chondromas are considered, they are specific and indicate the diagnosis. On CT scan, they can demonstrate variable degrees of calcifications resulting in hypodense to mixed density appearances. Hyperostosis or bony erosion of adjacent bone can occasionally be seen. ${ }^{5}$ Importantly, on contrast MRI, they are $\mathrm{T} 1$ isointense. ${ }^{6}$

\section{Histological Features}

Intracranial chondromas typically appear as well-differentiated cartilage lobules encapsulated by fibrous connective tissue. There is usually mild cellularity with no nuclear atypia or mitotic activity. As in other chondroid lesions, immunohistochemistry may show positivity for $\mathbf{S 1 0 0}$ and vimentin; however, immunostains are not required for the diagnosis.

\section{Observations}

Falcine intracranial chondromas are infrequently reported in the literature. We show that they can present without symptoms and are difficult to diagnose on imaging.

\section{Lessons}

Intracranial chondromas are rare, benign cartilaginous tumors. When their imaging features are considered, a high-probability preoperative diagnosis can be made and treatment structured accordingly.

\section{References}

1. Sarwar M, Swischuk LE, Schecter MM. Intracranial chondromas. AJR Am J Roentgenol. 1976;127(6):973-977.

2. Ahyai A, Spoerri O. Intracerebral chondroma. Surg Neurol. 1979; 11(6):431-433.

3. Doukas A, Tallo A, Parvin R, et al. Giant dural supratentorial chondroma generating the question of how large can a tumor become without revealing itself. Clin Pract. 2015;5(4):777.

4. Maheshwari V, Mehdi G, Varshney M, et al. Intracranial chondroma: a rare entity. BMJ Case Rep. 2011;2011: bcr0320114047.

5. Nakayama M, Nagayama T, Hirano $\mathrm{H}$, et al. Giant chondroma arising from the dura mater of the convexity. Case report and review of the literature. J Neurosurg. 2001;94(2):331-334. 
6. Sullivan JC, Goldsmith J, Rojas R, et al. Intracranial dural parafalcine chondroma: case report and systematic review of the literature. World Neurosurg. 2019;122:1-7.

7. Elhakeem AAS, Essa AA, Soliman RK. Chondroma of the falx cerebri: a case report and review of literature. Neuropathology. 2019;39(6):461-466

8. Hirschfeld L. Sur une tumor cartilagineuse de la base du crabe (Enchondrome). C R Sean Mem Soc Biol. 1851;3:94-96.

9. Berkmen YM, Blatt ES. Cranial and intracranial cartilaginous tumours. Clin Radiol. 1968;19(3):327-333.

10. Al Mohtaseb AH, Hallak AH, Aldaoud N, et al. Chondroma of the falx cerebri with central cystic degeneration and hemorrhage: a case report. Am J Case Rep. 2019;20:1331-1335.

11. Ozgen T, Pamir MN, Akalan N, et al. Intracranial solitary chondroma. Case report. J Neurosurg. 1984;61(2):399-401.

12. Colpan $E, A$ ttar A, Erekul S, et al. Convexity dural chondroma: a case report and review of the literature. J Clin Neurosci. 2003;10(1):106-108.

13. Mapstone TB, Wongmongkolrit T, Roessman U, et al. Intradural chondroma: a case report and review of the literature. Neurosurgery. 1983;12(1):111-114.

14. Sebbag M, Schmidt V, Leboucq N, et al. Dura mater chondroma. A case report and review of the literature. Article in French. $J$ Radiol. 1990;71(8-9):495-498.

15. Fountas KN, Stamatiou S, Barbanis S, et al. Intracranial falx chondroma: literature review and a case report. Clin Neurol Neurosurg. 2008;110(1):8-13.
16. Hamamoto Filho PT, de Souza Faleiros AT, de Oliveira MFA, et al. Chondroma of the falx cerebri. Rev Assoc Med Bras. 2015;61(1):17-18

17. Traflet RF, Babaria AR, Barolat $G$, et al. Intracranial chondroma in a patient with Ollier's disease. Case report. J Neurosurg. 1989; 70(2):274-276.

18. Chakrabortty S, Tamaki N, Kondoh T, et al. Maffucci's syndrome associated with intracranial enchondroma and aneurysm: case report. Surg Neurol. 1991;36(3):216-220.

\section{Disclosures}

The authors report no conflict of interest concerning the materials or methods used in this study or the findings specified in this paper.

\section{Author Contributions}

Conception and design: Chua, Bazarek, Saris. Acquisition of data: Chua. Analysis and interpretation of data: Chua, Meredith, Hsu, Saris. Drafting the article: Chua, Saris. Critically revising the article: Chua, Hsu, Saris. Reviewed submitted version of manuscript: all authors. Approved the final version of the manuscript on behalf of all authors: Chua. Administrative/technical/material support: Saris.

\section{Correspondence}

Melissa M. J. Chua: Brigham and Women's Hospital, Boston, MA. mchua@bwh.harvard.edu. 